УДК 612.576.51.76

DOI: https://doi.org/10.11603/mie.1996-1960.2020.2.11184

\title{
ІНФОРМАЦІЙНА ТЕХНОЛОГІЯ ДОСЛІДЖЕННЯ АДАПТАЦІЇ КЛІТКИ ДО ГІПОКСІї: У ЦЕНТРІ УВАГИ МІТОХОНДРІї
}

\author{
Міжнародний науково-навчальний центр інформаційних технологій \\ та систем НАН та МОН України
}

\begin{abstract}
На базі математичної моделі розроблено інформаційну технологію для дослідження адаптації клітини до гіпоксії шляхом перебудови окисної потужності мітохондрій різними способами. Розглянуто приклад їі застосування для розрахунку параметрів кисневого режиму клітини з різним розподілом мітохондрій. Порівняння кисневих режимів клітини з рівномірним і нерівномірним розподілом мітохондрій показало, що при гіпоксії підвищення окислювальної потужності рівномірно розподілених мітохондрій може збільшувати швидкість споживання кисню, при цьому гіпоксія в клітці зростає. Переміщення мітохондрій у напряму до капілярів і їх нерівномірний розподіл, за розрахунками, сприяло клітинній адаптації: удалося зменшити гіпоксію та підтримати швидкість споживання кисню на потрібному рівні. При погіршенні дисрузійного транспорту $\mathrm{O}_{2}$ перебудова мітохондрій розширює можливості клітини компенсувати погіршення умов дифузії.
\end{abstract}

Ключові слова: інформаційна технологія, кисневий режим клітини, гіпоксія, адаптація, інформаційна технологія, швидкість споживання кисню, розподіл мітохондрій, окисна потужність мітохондрій.

\section{INFORMATION TECHNOLOGY FOR THE STUDY OF CELL ADAPTATION TO HYPOXIA: THE FOCUS IS ON MITOCHONDRIA}

K. G. Liabakh

\author{
International Research and Training Center for Information Technologies and Systems \\ of National Academy of Sciences of Ukraine
}

Background. It is offered a concise description of the information technology to study the adaptation of cells to hypoxia by special redistribution of mitochondrial oxidative power by different ways. Our goal was to represent a concise description of this technology based on a mathematical model and propose an example of its application for calculating the parameters of cell oxygen mode under different ways of mitochondrial distribution.

Materials and methods. Results. Comparison of the oxygen regimes of the cell with a uniform and uneven distribution of mitochondria showed that during hypoxia, an increase in the oxidative power of evenly distributed mitochondria can increase the rate of oxygen consumption, while hypoxia in the cell increases. Under uneven of mitochondria distribution oxygen mode improved, hypoxia weakened. The movement of mitochondria towards the capillary is able to facilitate cellular adaptation. It was possible to reduce hypoxia and maintain the oxygen consumption rate at the constant level.

Conclusions. An information technology has been developed to calculate the parameters of the oxygen regime of the cell at various distributions of mitochondria in it. When $\mathrm{O}_{2}$ diffusion transport worsens, mitochondrial spatial rearrangement expands the cell's ability to compensate for the worsening diffusion conditions.

Key words: information technology, oxygen mode of a cell, hypoxia, adaptation, information technology, speed of oxygen consumption, distribution of mitochondria, oxidative power of mitochondria. 


\title{
ИНФОРМАЦИОННАЯ ТЕХНОЛОГИЯ ИССЛЕДОВАНИЯ АДАПТАЦИИ КЛЕТКИ К ГИПОКСИИ: В ЦЕНТРЕ ВНИМАНИЯ МИТОХОНДРИЯ
}

Е. Г. Лябах

\author{
Международный научно-учебный центр инорормационных технологий \\ и систем НАН и МОН Украины
}

\begin{abstract}
На базе математической модели разработана иноормационная технология для исследования адаптации клетки к гипоксии путем перестройки окислительной мощности митохондрий разными способами. Рассмотрен пример ее применения для расчета параметров кислородного режима клетки с разным распределением митохондрий. Сравнение кислородных режимов клетки с равномерным и неравномерным распределением митохондрий показало, что при гипоксии повышение окислительной мощности равномерно распределенных митохондрий может увеличивать скорость потребления кислорода, при этом гипоксия в клетке возрастает. Перемещение митохондрий по направлению к капилляру и их неравномерное распределение, по расчетам, способствовало клеточной адаптации: удалось уменьшить гипоксию и поддержать скорость потребления кислорода на нужном уровне. При ухудшении диффузионного транспорта $\mathrm{O}_{2}$ перестройка митохондрий расширяет возможности клетки компенсировать ухудшение условий дифрфузии.
\end{abstract}

Ключевые слова: инсормационная технология, кислородный режим клетки, гипоксия, адаптация, инсормационная технология, скорость потребления кислорода, распределение митохондрий, окислительная мощность митохондрий. 
Вступление. Главным условием жизни является приток свободной энергии, который обеспечивается в основном митохондриальным дыханием. Жизнь митохондрий зависит от физико-химических условий внутри клетки, в первую очередь, от ее кислородного режима, который сам, в свою очередь, зависит от митохондрий. Кислородный режим клетки (KPK) характеризуется распределением напряжения кислорода, $\mathrm{pO}_{2}$, которое формируется соотношением его доставки и расхода. $\mathrm{pO}_{2}$ в клетке влияет на два жизненно важных процесса: на тканевое дыхание и на производство активных форм кислорода, АФК. Регулирование КРК, таким образом, ответственно за поддержанием средней скорости потребления кислорода $\mathrm{VO}_{2}$ с и за нахождение внутриклеточного $\mathrm{pO}_{2}$ в определенных границах, дабы производство АФК митохондриями не росло. Решение двух обозначенных задач составляет суть регулирования KРК. С этих позиций будем рассматривать КРК при адаптации к гипоксии.

В последние 10-15 лет внимание научной общественности буквально приковано к огромному многообразию влияния митохондрий на жизнедеятельность клетки и всего организма, растет число публикации и научных конференций, посвященных новым данным о функциях митохондрий. Установлено, что энергетическое снабжение клетки определяет энергетический потенциал организма, от которого напрямую зависит его здоровье [1]. Митохондрии рассматривают как мишень в лечении стресса, нейро-дегенеративных болезней, рака, ишемии-реперфузии и многих других патологий. Успешная борьба с ними невозможна без понимания роли митохондрий в регулировании КРК.

Митохондрии - бактерии по своему происхождению, сохранили свойство двигаться, используя транспортные белки и эндоплазматический ретикулум. Их перемещение не ограничивается внутриклеточной средой. Обнаружено, что клетки могут обмениваться митохондриями для репарации повреждений. Такой обмен наблюдали между нейронами и астроцитами, в легких курильщиков, в миокарде при стрессе, в костной ткани. Здоровые остеоциты передавали митохондрии через дендритную сеть стрессированным остеоцитам с нефункциональными митохондриями. Донором митохондрий служила здоровая клетка, иногда стволовая, реципиентом - поврежденная. Повидимому, для выживания клетки могут согласованно сотрудничать, делясь своими ресурсами $[2,3]$.
Находясь, как правило, в движении внутри клетки, митохондрии сливаются (фьюжен) и расходятся (фижен), перемещаясь при гипоксии по направлению к источнику кислорода. Их скопление наблюдалось поблизости сосудов и в области высокой метаболической активности [4-7]. Предполагая, что неравномерное распределение митохондрий в клетке должно влиять на формирование KPK, нами разработано информационную технологию для исследования роли митохондрий в регулировании КРК при адаптации к гипоксии.

Цель работы: дать краткую характеристику разработанной информационной технологии (ИТ) и рассмотреть пример ее использования.

Материал и методы исследования. В фокусе нашего внимания - митохондрии, свободное перемещение которых внутри клетки создает неоднородность их распределения. Известно, что в зависимости от метаболического запроса $\mathrm{mr}$ и других факторов, активирующих окислительное фосфорилирование, мощность отдельной митохондрии может изменяться в возможных для нее пределах. Общее количество митохондрий в клетке и кислородный запрос определяют метаболическую нагрузку на отдельную митохондрию. Чем больше плотность митохондрий, тем меньше нагрузка на каждую из них. Чем больше потенциальная окислительная мощность отдельной митохондрии, тем больше возможная общая окислительная мощность митохондрий в элементарном объеме клетки. Нами использовано понятие удельной окислительной мощности, которая равна произведению окислительной мощности одной митохондрии на их количество в единице объема, т. е. на их плотность. Это понятие фигурирует в расчетах и результатах исследований КРК при помощи разработанной информационной технологии. Говоря об $\mathrm{mr}$ как удельной максимальной мощности митохондрий, кислородном запросе или о скорости потребления кислорода $\mathrm{VO}_{2}$ в элементарном объеме клетки, заметим, что только в случае полностью аэробного режима $\mathrm{VO}_{2} \mathrm{C}=\mathrm{mr}$.

Основой информационной технологии анализа KРК служит математическая модель транспорта $\mathrm{O}_{2}$ в клетке (миоците), который схематически изображаем в виде микроциркуляторной единицы МЦЕ - призмы, окруженной 4-мя капиллярами [8]. Модель описывает кислородный запрос (mr), $\mathrm{pO}_{2}$ - напряжение $\mathrm{O}_{2}$ в крови и в клетке, доставку $\mathrm{O}_{2}$ кровотоком с объемной скоростью $(\mathrm{k} 2)$ и объемной диффузией $\mathrm{O}_{2}$ к митохондриям из капиллярной сети 
с заданными параметрами - межкапиллярным расстоянием (dd) и длиной капилляра (ll) [8, 9]. Известна концентрация $\mathrm{O}_{2}$ в артериальной крови (c9), ее рН и кислородная емкость (ke). В модель включены коэффициент диффузии кислорода (d) и выбранный тип кинетики потребления $\mathrm{O}_{2}$ Михаэлис-Ментен: $\mathrm{VO}_{2}=\operatorname{mr}$ х pО $\mathrm{km}$ - константа Михаэлиса. О способе распределения мощности митохондрий, потребляющих кислород, в виде точечных стоков О 2 будет сказано ниже. Рассчитываются показатели $\mathrm{VO}_{2}$ и $\mathrm{pO}_{2}$ в объеме клетки, а также их средние значения $\mathrm{pO}_{2} \mathrm{t}, \mathrm{VO}_{2} \mathrm{c}$, минимальное тканевое $\mathrm{pO}_{2}-\mathrm{pO}_{2} \mathrm{~min}$ и $\mathrm{pO}_{2}$ в капилляре, в частности, в артериальной и венозной крови $\left(\mathrm{po}_{2} \mathrm{v}\right)$. В каждой точке клетки $(\mathrm{x}, \mathrm{y}, \mathrm{z})$ определяется су $=\mathrm{VO}_{2}(\mathrm{x}, \mathrm{y}, \mathrm{z}) / \mathrm{mr}(\mathrm{x}, \mathrm{y}, \mathrm{z})$ отношение, которое отражает гипоксию - степень удовлетворения кислородного запроса в расчетной точке; среднее значение су характеризует среднюю внутриклеточную гипоксию.

Технология позволяет решать прямую и обратную задачу. Прямая задача предполагает расчет $\mathrm{pO}_{2}$ и $\mathrm{VO}_{2}$ по заданным параметрам доставки и потребления $\mathrm{O}_{2}$ при равномерном распределении мощности митохондрий mr. Этой, уже традиционной задаче, посвящено множество работ, в том числе и наших. Для ее решения используется блок 1. Обратная задача предполагает по известным показателям или тем, которые можем рассчитать, подбор значения параметров, не измеренных или трудно измеряемых, относящихся к митохондриям и микроциркуляторному руслу, при которых достигается нужная скорость потребления $\mathrm{O}_{2}$. Сформулированная нами обратная задача, появилась как следствие нашей идеи, согласно которой увеличение максимальной мощности митохондрий позволяет регулировать КРК при гипоксии различной этиологии. Решая обратную задачу, выбираем распределение митохондрий при гипоксии и определяем, как оно изменит КРК, в частности уменьшит ли гипоксию, повлияет ли на скорость потребления $\mathrm{O}_{2}$. Для решения обратной задачи были разработаны блоки 2 и 3, работающие совместно с блоком 1. Параметры режима в блоке 2 были те же, что и в блоке 1.

Использование блока 2 с распределением митохондриальных мощностей по градиенту $\mathrm{pO}_{2}$, сформированному в блоке 1 , показало, что при гипоксической гипоксии «целенаправленное» распределение mr существенно улучшает КРК. Так при снижении концентрации $\mathrm{O}_{2}$ в артериальной крови распределение мощностей митохондрий позволило поддерживать скорость потребления кислорода $\mathrm{VO}_{2} \mathrm{C}$ постоянной, уменьшить или полностью устранить гипоксию [6]. То же подтвердилось при исследовании циркуляторной гипоксии. Возможности такой адаптации зависели от остальных параметров доставки и энергетических затрат клетки [9-11].

Блок 3, как и блок 2, также предназначен для исследования регуляции КРК с участием перераспределения митохондрий. Особенность состояла в том, что с помощью блока 1 рассчитывались параметры КРК в режиме гипоксии без перемещения митохондрий. Затем информация о градиентах напряжения кислорода и скоростей его потребления передавалась в блок 3, а митохондрии перестраивались в зависимости от этой информации, при этом возможность изменять их мощность mr сохранялась, после чего рассчитывались параметры нового исследуемого режима, в том числе удельная окислительная мощность митохондрий, распределенная в пространстве клетки пропорционально градиентам $\mathrm{po}_{2}$ (блока 1) с ее максимальным значением mr. Подчеркнем, что в блоке 3 могут быть заданы любые независимые от блока 1 параметры режима. Далее с помощью блока 3 получали характеристики нового КРК с заданным неравномерным распределением кислородного запроса.

Результаты и их обсуждение. В качестве примера рассмотрим результаты анализа КРК с помощью блока 1. Возьмем случай циркуляторной гипоксии: мышечная клетка работает с умеренной нагрузкой в условиях недостаточности местного кровотока k2 = 20 мл/мин/100г, mr = 3,577 мл/мин/100г, c9 $=0,19$, $\mathrm{ke}=0,2, \mathrm{pH}=7,3$. Согласно расчетам, в случае равномерного распределения митохондрий (блок 1), рост межкапиллярного расстояния dd с $4 \times 10^{-3}$ см до $5,5 \times 10^{-3} \mathrm{~cm}$ и скорости кровотока $\mathrm{k} 2=20$ мл/мин/100г для поддержания $\mathrm{VO}_{2} \mathrm{c}=3,577$ мл/мин/100г потребовал увеличения мощности митохондрий mr с 4 мл/мин/100г до 6, 4 мл/мин/100г (рис. 1, режимы № 1-3, табл. 1). На рис. 1 показаны графики $\mathrm{VO}_{2}$ между венозным концом капилляра и точкой наихудшего снабжения $\mathrm{O}$.

В табл. 1 приведены характеристики КРК под номерами режимов, которые соответствуют номерам кривых на рис. 1. По величине су заключаем: с увеличением межкапиллярного расстояния dd гипоксия усиливается, так как су и скорость потребления кислорода уменьшаются. 


\section{VO2 мл/мин./100г}

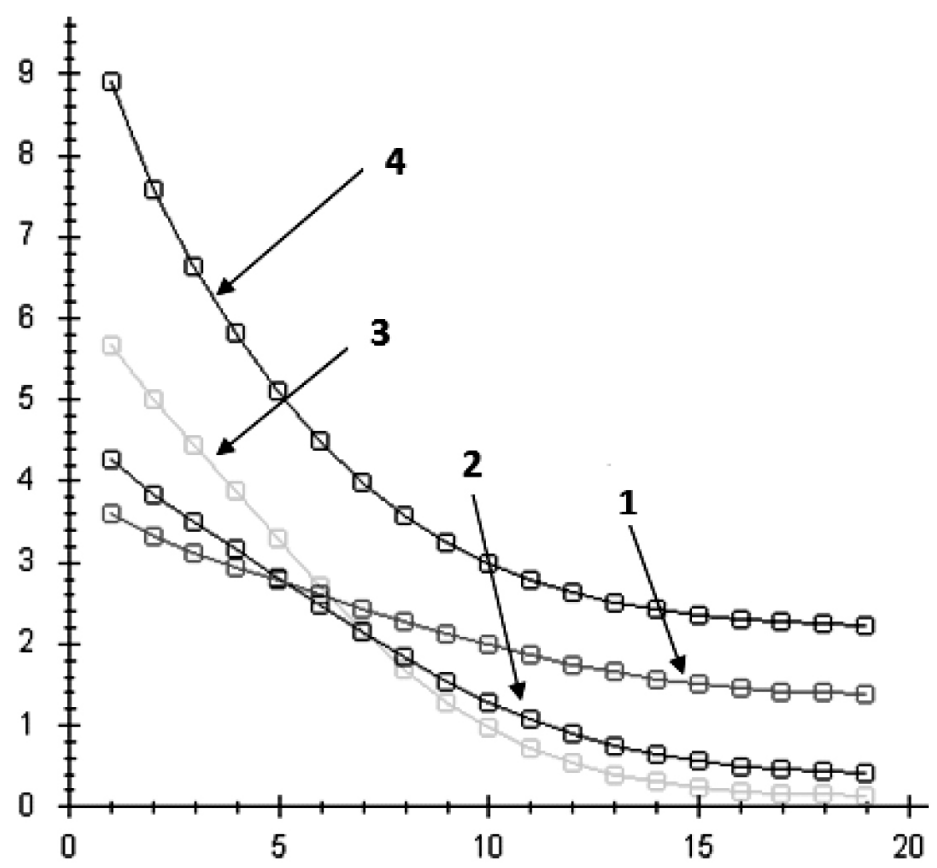

Рис. 1. Скорость потребления кислорода на линии между венозным концом капилляра (т. 0) и точкой наихудшего снабжения (т. 19) как характеристика КРК в разных режимах. Номерам кривых соответствуют данные режимов под такими же номерами в табл. 1

Параметры четырех вариантов КРК: № 1 - № 3 - с равномерно, № 4 - с неравномерно распределенными митохондриями

\begin{tabular}{|c|c|c|c|c|}
\hline $\begin{array}{c}\text { № } \\
\text { режима }\end{array}$ & $\begin{array}{c}\mathrm{dd}, \\
\text { см-4 }\end{array}$ & $\begin{array}{c}\mathrm{mr}, \\
\text { мл/мин/100г ткани }\end{array}$ & $\begin{array}{c}\mathrm{VO}_{2} \mathrm{c}, \\
\text { мл/мин/100г ткани }\end{array}$ & $\begin{array}{r}\mathrm{CY}, \\
\%\end{array}$ \\
\hline 1 & 40 & 4,00 & 3,577 & 89,4 \\
\hline 2 & 50 & 4,78 & 3,577 & 74,8 \\
\hline 3 & 55 & 6,40 & 3,577 & 55,9 \\
\hline 4 & 55 & 10,75 & 3,577 & 58,6 \\
\hline
\end{tabular}

Цель эксперимента с использованием блока 3 состояла в выяснении влияния на КРК выбранного неравномерного распределения митохондрий. C помощью блока 3 получали характеристики КРК с заданным неравномерным распределением кислородного запроса и входными параметрам, такими же как и в блоке 1 , хотя в общем случае параметры режима в блоке 3 , как уже упоминалось, могут быть любыми. Нами не изменялись входные значения для блока 3, чтобы сравнить как выбранное распределение окислительных мощностей митохондрий влияет на КРК.

Расчет КРК в новых условиях (блок 3) показывает, что при $\mathrm{dd}=5,5 \times 10^{-3}$ см и значительном увеличении максимального значения $\mathrm{mr}$ до 10,75 мл/ мин/100г достигается нужный результат: $\mathrm{VO}_{2} \mathrm{C}=$
3,577 мл/мин/100г. При этом су $=58,6$ \% возрастает по сравнению с су = 55,9 \% при равномерном распределении МХ. Следовательно, некий другой вариант распределения митохондрий может создать КРК с менее выраженной гипоксией (табл. 1 строка 4 и рис. 1 кривая 4).

Сравнение режимов, в которых получены средние значения су $=55,9 \%$ и су $=58,6 \%$ и су в каждой расчетной точке, представлено рис. 2.

Информационная технология позволяет рассчитать су в каждой точке объема клетки и представить характеристики кислородного режима - су и $\mathrm{pO}_{2}$ - в самом неблагоприятном месте клетки, на линии между венозным концом капилляра и точкой наихудшего снабжения О. Верхние кривые соответствуют режиму с неравномерным 


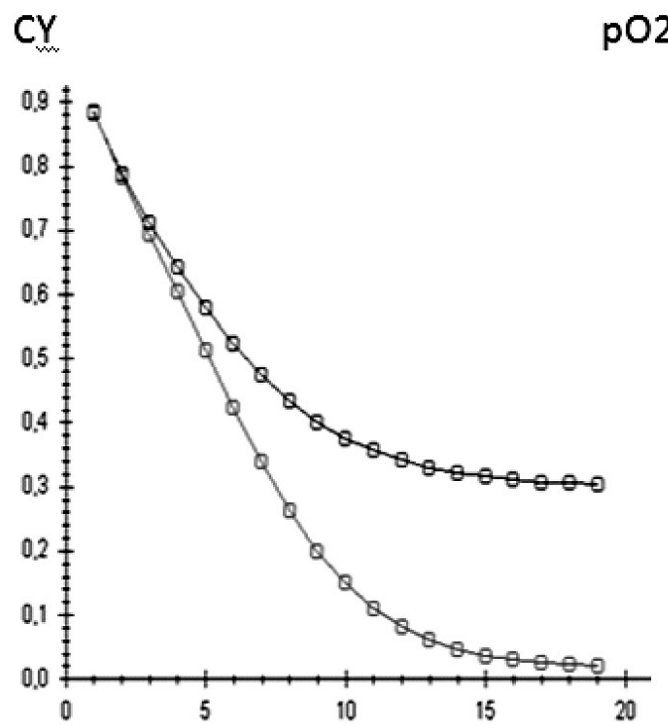

рO2 мм рт.ст.

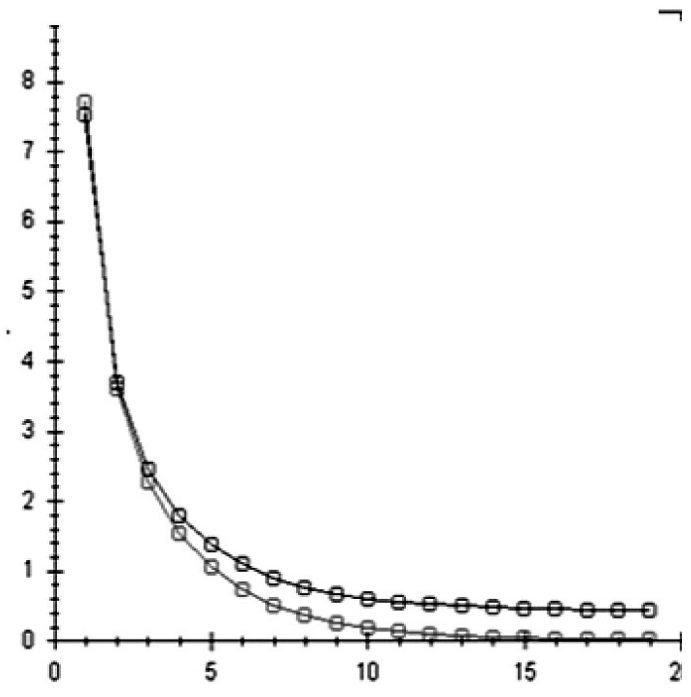

распределением, нижние - с равномерным распределением мощности митохондрий. Видно, как ослабляется гипоксия в объеме клетки при неравномерном распределении митохондрий.

Полученное распределение су - степень удовлетворения кислородного запроса в расчетной точке - называем «портретом» гипоксии. Рассматриваем его в сечении МЦЕ, проходящем через капилляр с артериальным и венозным концами A, V и точку O, которая лежит на оси симметрии МЦЕ, параллельной капилляру (рис. 3), который наглядно характеризует гипоксию в клетке [8, 9]. (Показана половина симметричного портрета гипоксии). Слева отображен режим равномерного, справа - неравномерного распределения митохондрий. Темная область в сечении МЦЕ нормроксия, светлая - гипоксия, она усиливается в направлении точки наихудшего снабжения О.

Как видно, более обширная и менее глубокая гипоксия наблюдается при существенной неравномерности распределения $\mathrm{mr}=10,75$ мл/ мин/100г (блок 3) по сравнению с режимом $\mathrm{mr}=$ 6,4 мл/мин/100г (блок 1) при меньшей мощности митохондрий, распределенных равномерно. Численные данные рядом с «портретом» гипоксии - это входные и расчетные параметры КРК в вычислительном эксперименте. Расчеты убеждают в том, что, во-первых, при ухудшении диффузии $\mathrm{O}_{2}$ равномерно распределенные митохондрии могут способствовать поддержанию

скорости потребления $\mathrm{O}_{2}$ на нужном уровне, если их окислительная мощность будет расти, но при этом гипоксии усилится. Во-вторых, неравномерно распределенные митохондрии могут не только обеспечить $\mathrm{VO}_{2}=$ const, но и ослабить гипоксию.

Нужно подчеркнуть, что перестройка митохондрий в реальных клетках может выполнять одну или несколько разных физиологических задач и регулирование КРК является важнейшей, но не единственной из них! Следовательно, возможные варианты распределения митохондрий, необходимые для других целей не обязательно будут лучшими для регулирования КРК, но сочетание количества митохондрий и их потенциальная мощность - 2 степени свободы, дают некоторый простор для свободы их выбора при в регуляции КРК. Работая с технологией, смогли физически обосновать гипотезу, согласно которой при гипоксии митохондрии могут регулировать КРК разными способами. Предложенная технология позволяет рассматривать эти способы, что дает возможность в дальнейшем изучать влияние реорганизации митохондрий, возникшей при одном режиме, в адаптации клетки к работе в другом режиме.

Заключение. Три блока разработанной нами информационной технологии применимы в специфических и, судя по данным литературы, типичных случаях распределения митохондрий в клетке. В будущем есть возможность расширить применение технологии для изучения КРК в условиях пространственных 


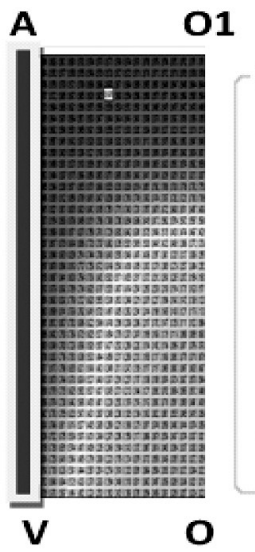

\begin{tabular}{|c|c|c|c|}
\hline \multicolumn{4}{|c|}{ Входные параметры блока 1 - } \\
\hline c9: & 0,19 & \\
\hline k2: & 20 & & \\
\hline$\|$ : & 0,1 & \multicolumn{2}{|c|}{ Вьводы блока1 - } \\
\hline mer : & 6,4 & \multirow{5}{*}{$\begin{array}{l}\text { vo2c } \\
\mathrm{pO} 2 \mathrm{a} \\
\mathrm{pO} 2 \mathrm{v} \\
\mathrm{pO} 2 \mathrm{t} \\
\mathrm{pO} 2 \mathrm{~min} \\
\mathrm{cy} \\
\text { avd }\end{array}$} & \multirow{5}{*}{$\begin{array}{l}3,577 \\
85,189 \\
6.676 \\
7,064 \\
0,023 \\
0.559 \\
0,179\end{array}$} \\
\hline $\mathrm{km}$ : & 0,01 & & \\
\hline dd: & 0,0055 & & \\
\hline ke: & 0,2 & & \\
\hline $\mathrm{pH}:$ & 7,3 & & \\
\hline
\end{tabular}

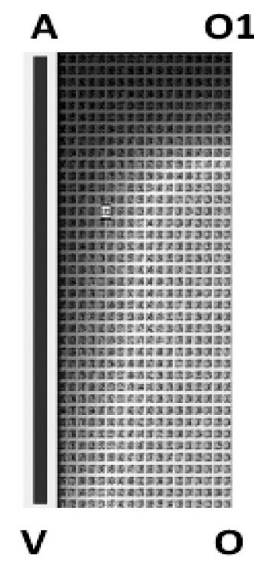

\begin{tabular}{|c|c|c|c|}
\hline \multicolumn{2}{|c|}{ эходные параметры блока 3} & \multirow{4}{*}{\multicolumn{2}{|c|}{ Выводы блока 3}} \\
\hline c9: & 0,19 & & \\
\hline k2: & 20 & & \\
\hline \multirow{2}{*}{$\begin{array}{l}\text { II: } \\
\text { mer : }\end{array}$} & 0,1 & & \\
\hline & 10,75 & \multirow{5}{*}{$\begin{array}{l}\mathrm{vO2c} \\
\mathrm{pO} 2 \mathrm{a} \\
\mathrm{pO} 2 \mathrm{v} \\
\mathrm{pO} 2 \mathrm{t} \\
\mathrm{pO} 2 \mathrm{~min} \\
\mathrm{cy}\end{array}$} & \multirow{4}{*}{$\begin{array}{l}3,577 \\
85,189 \\
6,607 \\
4,984 \\
0,470\end{array}$} \\
\hline $\mathrm{km}$ : & 0.01 & & \\
\hline dd: & 0,0055 & & \\
\hline ke: & 0,2 & & \\
\hline pH: & 7,3 & & $\begin{array}{l}0,586 \\
0,179\end{array}$ \\
\hline
\end{tabular}

Рис. 3. Портрет гипоксии расчетные значения СУ в сечении миоцита, проходящем через капилляр $\mathrm{AV}$ и точку $\mathrm{O}$ - центр миоцита. Темная область - нормоксия, светлая - гипоксия, которая усиливается в направлении зоны наихудшего снабжения точки О. Справа соответствующие входные и выходные параметры КРК в 2-х режимах циркуляторной гипоксии в условиях разных расположений митохондрий и разных значений окислительной мощности.

гетерогенностей и анизотропии, например, диффузионных свойств внутри клетки, рассмотреть субсарколеммальные и интермиофибриллярные митохондрии, соседство красных и белых мышщ, а также и перейти к использованию результатов микроскопических исследований на реальных клетках.

Выводы. 1. Разработана информационная технология для расчета параметров кислородного режима клетки при различных распределениях в ней митохондрий.
2. В условиях гипоксии повышение окислительной мощности митохондрий может увеличивать скорость потребления кислорода. Перемещение митохондрий в направлении к капилляру способствует клеточной адаптации: уменьшает гипоксию, вплоть до полного устранения.

3. Рост окислительной мощности митохондрий и их перераспределение в клетке расширяет ее возможности компенсировать ухудшение условий внутриклеточной диффузии $\mathrm{O}_{2}$. 


\section{Литература.}

1. Апанасенко Г. Л. Индивидуальное здоровье: теория и практика. Введение в теорию индивидуального здоровья / Апанасенко Г. Л. - К.: Медкнига, 2011. -108 c

2. Mitochondria Know No Boundaries: Mechanisms and Functions of Intercellular Mitochondrial Transfer / Torralba D., Baixauli F., Sanchez-Madrid F. — Frontiers in-Cell and Developmental Biology, 28 sept. 2016.

3. Endoplasmic reticulum mediates mitochondrial transfer within the osteocyte dendritic network / J. Gao, A. Qin, D. Liu // Science Advances. — 2019. — Vol. 5, No. 11. - P. 1-12.

4. The similarity of mitochondrial distribution in equine skeletal muscle of differing oxidative capacity / Kajar S. R., Hoppeler H., Essen-Gustavson B., Scherzmann K. // Journal Experimental Biology. — 1988. Vol. 137. - P. 253-263.

5. During hypoxia, HUIMMR joins the mitochondrial dance / Li Y., Rempe D. A. // Cell Cicle. - 2010. — Vol. 9, No1. - P. 50-57.

6. Oxidative power and intracellular distribution of mitochondria control cell oxygen regime when arterial hypoxemia occurs / Lyabakh K. G., Lissov P. N. // Biophysics. - 2012. — Vol. 57, No 5. - P. 628-633.

7. A model for intracellular energy transport / Mainwood G., Rakusan K. // Canadien Journal of Physiology and Pharmacology. - 1982. - Vol. 60, No 1. - P. 98-102.

8. Lyabakh K. G. Mathematical modeling of oxygen transport in skeletal muscle during exercise: hypoxia and VO2 max / Lyabakh K. G. // Advanced Experimental Medicine and Biology. — 1999. — Vol. 471. P. 585-593.

9. Oxygen transport to skeletal muscle working at VO2max in acute hypoxia: theoretical prediction / Lyabakh K. G., Mankovskaya I. N. // Comparative Biochemistry and Physiology, Part A. — 2002. — Vol. 132. - P. 53-60.

10. Liabakh K. G. Oxidative power and intracellular distribution of mitochondria regulate cell oxygen regime under circulatory hypoxic / Liabakh K. G. // International Journal of Physiology and Pathophysiology. — 2018. — Vol. 9, No 1. - P. 1-11.

11. Лябах К. Г. Регуляція кисневого режиму клітини, заснована на дифузії / Лябах К. Г. // Фізіол. журн. - 2019. - T. 65, № 3. - С. 12-21.

\section{References.}

1. Apanasenko, G. L. (2011). Individual health: theory and practice. Introduction to the theory of individual health. Kiev: Medknyga. [In Russian].

2. Torralba, D., Baixauli, F., Sanchez-Madrid F. (2016). Mitochondria Know No Boundaries: Mechanisms and Functions of Intercellular Mitochondrial Transfer. Frontiers in-Cell and Developmental Biology.

3. Gao, J., Qin, A., Liu, D. (2019). Endoplasmic reticulum mediates mitochondrial transfer within the osteocyte dendritic network. Science Advances, 5:11, 1-12.

4. Kajar, S. R., Hoppeler, H., Essen-Gustavson, B., Scherzmann, K. (1988). The similarity of mitochondrial distribution in equine skeletal muscle of differing oxidative capacity. Journal Experimental Biology, 137, 253-63.

5. Li, Y., Rempe, D. A. (2010). During hypoxia, HUIMMR joins the mitochondrial dance. CellCicle, 9:1, 50-7.

6. Lyabakh, K. G., Lissov, P. N. (2012). Oxidative power and intracellular distribution of mitochondria control cell oxygen regime when arterial hypoxemia occurs. Biophysics, 57:5, 628-33.

7. Mainwood, G., Rakusan, K. (1982). A model for intracellular energy transport. Canadien Journal of Physiology and Pharmacology, 60:1, 98-102.

8. Lyabakh, K. G. (1999). Mathematical modeling of oxygen transport in skeletal muscle during exercise: hypoxia and VO2 max. Advanced Experimental Medicine and Biology, 471, 585-93.

9. Lyabakh, K. G., Mankovskaya, I. N. (2002). Oxygen transport to skeletal muscle working at VO2max in acute hypoxia: theoretical prediction. Comparative Biochemistry and Physiology, Part A, 132, 53-60 .

10. Liabakh, K. G. (2018). Oxidative power and intracellular distribution of mitochondria regulate cell oxygen regime under circulatory hypoxic. International Journal of Physiology and Pathophysiology, 9:1, 1-11.

11. Liabakh, K. G. (2019). Regulation of cell oxygen regime based on diffusion. Journal of Physiology, 65:3, 12-21. [In Ukranian]. 